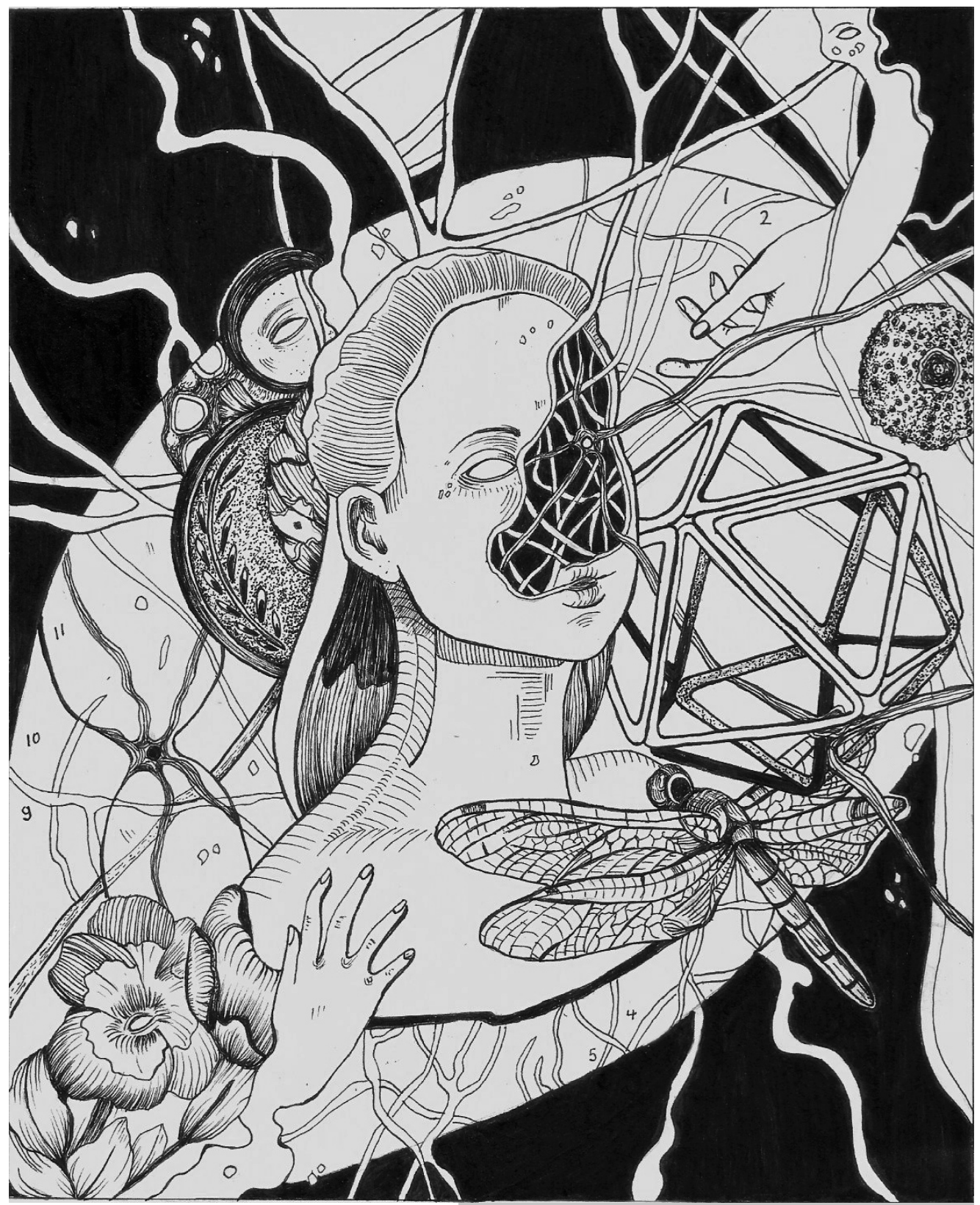

Artista invitada

Elizabeth Rivera Cardona

De la serie Identities

Rapidógrafo en papel aralda 2020

Cortesía Revista Ojo de Pez 


\title{
La (re)irrupción del discurso de la «ideología de género» en América Latina. Protestas, atención del público y respuestas gubernamentales*
}

\author{
Jairo Antonio López Pacheco (Colombia)**
}

\section{Resumen}

El artículo indaga las características de los principales episodios de protesta convocados por los grupos conservadores contra políticas como el reconocimiento del matrimonio igualitario, la identidad de género y la incorporación de componentes de educación sexual y reproductiva en libros de texto escolares en América Latina entre 2016 y 2018. Desde el marco analítico de la acción colectiva se definen estas acciones como reacciones reactivas y preventivas frente al avance de los derechos sexuales y reproductivos, identificando como elemento común un reposicionamiento en el escenario público e interés ciudadano de la idea de la «ideología de género», asociado a la visibilidad de las marchas y protestas escenificadas en cada país. Se identifica que, frente a estas formas de comunicar y difundir las demandas de los grupos conservadores en el ámbito regional, los gobiernos nacionales tienen como principal respuesta llamados públicos a la "calma», dando marcha atrás a las reformas propuestas, cediendo a la presión y legitimando las acciones que buscan presentar el reconocimiento de los derechos humanos como una amenaza.

\section{Palabras clave}

Esfera Pública; Reacción Conservadora; Movimiento Conservador Trasnacional; Derechos Sexuales y Reproductivos; Ideología de Género; América Latina.

Fecha de recepción: junio de 2020 - Fecha de aprobación: noviembre de 2020

\footnotetext{
* Artículo producto de la investigación Conflictos por los derechos sexuales y reproductivos en América Latina. Disputas socioculturales y políticas, adscrita al Centro de Estudios de la Cultura y la Comunicación, Universidad Veracruzana, México.

${ }^{* *}$ Sociólogo. Doctor en Investigación en Ciencias Sociales. Profesor e investigador de la Universidad Veracruzana, México. Correo electrónico: jairolopez32@gmail.com - Orcid: 0000-0003-4877-6708 Google Scholar: https://scholar.google.com/citations?user=gsP6UfIAAAAJ\&hl=es
} 


\title{
Cómo citar este artículo
}

López Pacheco, Jairo Antonio. (2021). La (re)irrupción del discurso de la «ideología de género» en América Latina. Protestas, atención del público y respuestas gubernamentales. Estudios Políticos (Universidad de Antioquia), 60, pp. 145-177. DOI: 10.17533/udea.espo.n60a07

\section{The (re) Irruption of Gender Ideology Discourse in Latin America. Protests, Public Attention, and Government Responses}

\begin{abstract}
The article analyzes the main features of the protest episodes called by conservative groups against policies such as the recognition of equal marriage, gender identity, and the incorporation of school textbooks about sexual and reproductive education between 2016 and 2018 in Latin America. These actions are defined from the analytical framework of collective action as reactive and preventive replies to the advancement of sexual and reproductive rights. As a common factor, it was identified a positioning in the public arena and an interest in the idea of "gender ideology» associated with the visibility of protests by conservative groups in each country. The main response by the national governments was to make public calls for "calm», reversing the proposed reforms, giving in to pressure, and legitimizing actions that seek to present the recognition of human rights as a threat.
\end{abstract}

\section{Keywords}

Public Sphere; Conservative Backlash; Transnational Conservative Movement; Sexual and Reproductive Rights; Gender Ideology; Latin America. 
La (re)irrupción del discurso de la «ideología de género» en América Latina...

\section{Introducción}

Uno de los fenómenos socioculturales y políticos más importantes de la última década en América Latina ha sido el creciente protagonismo de las iglesias en la dinámica electoral y su influencia en la toma de decisiones de política pública. Diversos grupos conservadores y religiosos —con especial protagonismo de la Iglesia católica y las iglesias pentecostales y neopentecostales - hicieron explícita su intención de obtener poder político electoral, amenazando - paradójicamente, bajo el argumento de la «libertad religiosa»— los principios propios del Estado Laico (Corrales, 2018, January 17). Con elecciones presidenciales, estatales, parlamentarias o referendos en gran parte de la región se abrió un espacio que aumentó su protagonismo amparado, entre otros, en un férreo rechazo al reconocimiento de los derechos de las mujeres y la personas lesbianas, gais, bisexuales y trans (LGBT), impulsando la idea de que se oponen a lo que denominan como la expansión de la «ideología de género» (Arguedas, 2020; Biroli y Caminotti, 2020; López, 2017; Pérez y Rocha, 2020).

Las estrategias de movilización de los grupos conservadores contra los derechos sexuales y reproductivos han sido definidas como «políticas antigénero» (Arguedas, 2020; Kuhar y Paternotte, 2017), «politización de la religión» (Felitti, 2011; Vaggione, 2005), impulso de «fundamentalismos religiosos» (Bárcenas, 2018; Ruibal, 2014; Vaggione, 2010) o «Contramovimientos conservadores» (Gianella, 2018; Lemaitre, 2013; López, 2017). Igualmente, se ha problematizado la intersección que existe entre religión y sexualidad en los marcos jurídicos de gran parte del continente y que estos grupos defienden promoviendo una interpretación de la ley basada en el «derecho natural»(Lemaitre, 2013; Morán, Sgró y Vaggione, 2012; Sáez y Morán, 2016; Vaggione y Mujica, 2013), siguiendo estrategias de secularismo estratégico que impulsan argumentos que apelan a la ciencia y la bioética para oponerse a los derechos (Felitti, 2011; Lemaitre, 2013; Morán y Morgan, 2005; Vaggione, 2005; 2012). En todos los estudios se da un énfasis a la dimensión religiosa, explicando los conflictos en términos de resistencias a prácticas que no reproducen los patrones heteronormativos y heteropatriarcales de la sexualidad (Morán, 2018; Sáez y Morán, 2016).

Ahora bien, dado que es claro que estas acciones conservadoras hacen parte de un fenómeno global-regional y que apuntan a la incidencia política, es importante preguntarse: ¿qué tipo de estrategias compartidas siguen los 
movimientos conservadores para influir en la toma de decisiones? y icuál ha sido el rol de los gobiernos como objeto de dichas presiones en América Latina? Para dar respuesta a estas preguntas, en el presente artículo se abordan las características de los principales episodios de protesta convocados por los grupos conservadores contra políticas como el reconocimiento del matrimonio igualitario, la identidad de género y la incorporación de manuales de educación sexual y reproductiva en Colombia, Ecuador, México, Panamá, Paraguay, Perú y Bolivia entre 2016 y 2018.

La elección del periodo se debe a que se representó una coyuntura clave de articulación de las organizaciones conservadoras que se oponen a los derechos sexuales y reproductivos en el ámbito regional, presentándose una clara vinculación transnacional con tres tipos de actores centrales: jerarquías de la Iglesia católica y las iglesias evangélicas pentecostales y neopentecostales; líderes de organizaciones y partidos políticos; organizaciones civiles que aumentaron su coordinación al interior de los países y en el ámbito continental, autoidentificándose como defensoras de los derechos de los padres y los niños, bajo eslóganes como \#ConMisHijosNoTeMetas, \#AMisHijosLosEducoYo o \#NoEsBiologíaEsldeología.

En este artículo se argumenta que la movilización conservadora ha generado una exitosa estrategia de (re)irrupción del término «ideología de género» en el escenario público, reflejado en indicadores de atención ciudadana como marco que aglutina demandas contra los derechos sexuales y reproductivos, tanto en países donde las agendas de reconocimiento de derechos han avanzado formalmente — reacción reactiva-como en aquellos donde aún no han sido reconocidos los derechos — reacción preventiva-. Ante estas formas de comunicar y difundir las demandas de los movimientos conservadores, la principal respuesta de los gobiernos nacionales ha sido la exposición de llamados a la «calma», cediendo a la presión y legitimando las posiciones de actores que se oponen al avance de los derechos humanos.

La sistematización cronológica de los principales eventos de protesta convocados bajo el discurso de la «ideología de género» se presenta a partir de un rastreo de prensa, comparando los patrones que se repiten a partir de la caracterización de los objetivos de los reclamos, los actores que convocan y las coyunturas de su manifestación (Tilly, 2011). Para analizar la difusión del marco de la reacción, se relacionan las coyunturas de protesta en cada país con el indicador de búsquedas realizadas en Google del término «ideología de género», siguiendo la recomendación metodológica de Lance Bennett, 
Alexandra Segerberg y Yunkang Yang (2018), según la cual este indicador permite acercarse al interés generado por las demandas de los movimientos pues, en términos generales, los marcos de las demandas pueden irrumpir y generar tendencias de interés donde antes no se encontraban indicios de atención de las personas sobre estas ideas. Finalmente, se rastrean las respuestas públicas de los gobiernos objeto de las demandas, ya que en la voz autorizada de los gobiernos se puede comprender el tipo de influencia e incidencia en la toma de decisiones públicas que generaron los reclamos articulados bajo el discurso de la «ideología de género».

\section{Las protestas contra los derechos sexuales y reproductivos como una reacción conservadora}

Las investigaciones en torno a la expansión y socialización de los derechos humanos han evidenciado que las leyes e instituciones internacionales de derechos humanos, el activismo transnacional y la existencia de movimientos sociales son mecanismos que inciden de manera determinante en el reconocimiento y cumplimiento de los derechos humanos (Dancy y Sikkink, 2017). Si bien existe un creciente consenso en torno a los factores que permiten el avance de la socialización de los derechos, es menor la sistematización sobre los factores que, una vez reconocidos, pueden generar retrocesos o límites. En tal sentido, en la literatura especializada se utiliza el término backlash ${ }^{1}$ para aludir a las «reacciones», «contragolpes»o «resistencias» frente al avance de los derechos humanos (Vinjamuri, 2017).

En términos generales, la reacción a los derechos es la manifestación de resistencias a pérdidas de privilegio y modificaciones del statu quo que afectan a grupos con capacidad de movilización (Mansbridge y Shames, 2008). Si bien no todos los movimientos por derechos generan las mismas resistencias, por lo general se produce o exacerba una fuerte reacción cuando hay dinámicas que presentan amplias, profundas y aceleradas conquistas en materia de derechos.

La reacción se explica por] la relación entre un régimen legal promulgado para efectuar el cambio social y el sistema de normas preexistentes y prácticas institucionalizadas en las que se introduce.

\footnotetext{
${ }^{1}$ Una de las primeras elaboraciones en torno al término backlash se encuentra en la obra de la feminista Susan Faludi (1991), quien analizó la respuesta conservadora a las conquistas de las mujeres durante el gobierno de Reagan en Estados Unidos.
} 
Específicamente, la reacción tiende a surgir cuando la aplicación de un régimen legal transformativo genera resultados que divergen demasiado bruscamente de las normas e instituciones arraigadas a las que los segmentos influyentes de la población conservan una lealtad fuerte (Hamilton, 2003, p. 341).

Los análisis sobre la reacción frente a los derechos humanos han mostrado que esta presenta diversas lógicas, que pueden ir desde la resistencia a la propia idea de los derechos bajo argumentos de defensa de la soberanía estatal, el impulso de alianzas electorales que garanticen mecanismos para el retroceso, hasta la estrategia de generación de «pánico moral» para movilizar población (Bob, 2012; Flores y Barclay, 2016; Vinjamuri, 2017).

Metodológicamente, es importante delimitar cuatro elementos para el análisis de la reacción y sus efectos: primero, la reacción no es solo la respuesta a una política implementada, lo que se puede definir como reacción reactiva, también puede tomar la forma de reacción preventiva a la amenaza de reconocimiento de ciertos derechos aún no reconocidos, pero que se presentan como cambios muy probables; segundo, la reacción es una acción organizada que comparte rasgos propios de toda acción colectiva contenciosa, como son las estructuras de movilización, los repertorios y la interacción con oportunidades políticas y jurídicas (Ruibal, 2015); tercero, la lógica de la reacción puede tener como objetivo bloquear una política concreta o generar estrategias de incidencia a mediano y largo plazo, buscando reestablecer los privilegios perdidos o reforzar los amenazados (Vinjamuri, 2017); cuarto, la intervención en la reacción puede contar con la participación de una gran variedad de actores, localizados tanto en los ámbitos nacional como internacional, y con una fuerza de presión que puede venir desde abajo movimientos, organizaciones, colectivos, ciudadanos(nas), grupos de baseo desde arriba — grupos de élite, gobiernos, actores institucionales-.

El avance de los derechos sexuales y reproductivos, como el derecho de las mujeres a decidir sobre su propio cuerpo, materializado en la posibilidad de acceder a educación sexual de calidad o a la interrupción legal del embarazo, cuestiona y trastoca los principios morales y privilegios que sustentan la visión de la sexualidad y la reproducción propia del orden heteropatriarcal, en la medida que brindan autonomía a las mujeres sobre sus trayectorias vitales. De la misma forma, derechos como el matrimonio entre personas del mismo sexo o la posibilidad de acceder a cambios de identidad de género trastocan principios morales sobre los que se ha definido la familia y la identidad (Sáez y Morán, 2016). En este sentido, las acciones de los grupos conservadores se presentan 
como una reacción o contramovilización, en tanto responden al consistente reconocimiento y legitimidad de los derechos exigidos por los movimientos de mujeres y de la diversidad sexual, los mismos que han sido reconocidos como derechos humanos y avanzado paulatinamente al interior de los países.

\section{El discurso de la «ideología de género» como marco de la reacción conservadora}

Como parte de la reacción para oponerse a los derechos sexuales y reproductivos, los movimientos conservadores construyen marcos de movilización, entendidos como las ideas, representaciones y discursos que unifican, dan sentido y orientan la acción colectiva (Benford y Snow, 2000; Tarrow, 2004). La reacción contra los derechos sexuales y reproductivos ha encontrado en el marco de la «ideología de género» una idea común de definición de los derechos sexuales y reproductivos como un conjunto de construcciones «anti-naturales» que aglutinan la movilización de su disenso. Investigaciones recientes han señalado que el marco de la «ideología de género» tiene efectos al interior de los actores y organizaciones conservadoras — que no son necesariamente uniformes y monolíticos-, donde la construcción de una cruzada contra la «ideología de género» ha generado efectos performativos y de reforzamiento de la identificación individual y colectiva con ideas morales y religiosas (Carnac, 2020).

La construcción del término «ideología de género» es rastreable, por lo menos, desde los debates de la Iglesia católica argentina hacia finales de la década de 1980, teniendo una creciente difusión global en la década de 1990 (Morán, 2019). Tras estos antecedentes, el término «ideología de género» se consolidó al interior de la Iglesia católica cuando fue acuñado por el papa Juan Pablo ॥ y el Vaticano, en alianza con grupos evangélicos y Estados católicos y musulmanes, como respuesta al consistente avance de los derechos de las mujeres en las Conferencias de El Cairo (1994) y Beijing (1995). Desde ese momento, el término «ideología de género» fue utilizado para denunciar la supuesta existencia de un cuerpo de ideas académicas y políticas que se presentan como una especie de revolución cultural contra la biología, manteniendo en el centro de su argumentación la defensa de un orden natural, propio del derecho canónico, que asocia al género, el sexo y la sexualidad con patrones fijos heteropatriarcales (Kuhar y Paternotte, 2017; Miskolci y Campana, 2017).

El liderazgo de la Iglesia católica en la creación y difusión del discurso de la «ideología de género» se centró en criticar y cuestionar 
a los organismos internacionales, como la Organización de Naciones Unidas. Esta posición fue permanente durante el inicio del siglo XxI, primero bajo el papado de Benedicto xvı quien fue conocido por sus posiciones ultraconservadoras en la defensa de la familia tradicional, y posteriormente durante el papado de Francisco, que a pesar de presentar un discurso aparentemente renovador sobre temas como la moral sexual, continuó refiriéndose a la «ideología de género» como una amenaza para los derechos humanos, una imposición colonialista y una deformación del individuo y de la naturaleza (Vaggione, 2020).

Esta estrategia discursiva se inscribe en lo que se caracteriza como el activismo católico conservador y el secularismo estratégico (Vaggione, 2020), es decir, el uso e impulso por parte de actores religiosos, o con estrechos vínculos con la Iglesia católica, de estrategias políticas y jurídicas para oponerse al avance de los derechos a partir de discursos aparentemente seculares. Si durante el siglo xx la acción de la reacción conservadora estuvo centrada en denunciar los «peligros» de la agenda internacional que impulsa los derechos humanos sexuales y reproductivos, uno de los elementos novedosos de estas respuestas durante el siglo xxı ha sido la coordinación creciente, liderada por las iglesias y asociaciones civiles, para promover estas reacciones, discursos [152] y agendas al interior de los Estados. Aunado a esto, la emergencia en el escenario público y político latinoamericano de grupos y organizaciones religiosas evangélicas pentecostales y neopentecostales estuvo estrechamente vinculada con una apropiación y difusión de este mismo marco de ideas (Bárcenas, 2018), estableciendo, en muchos casos, alianzas políticas sin precedentes entre las iglesias para adelantar una cruzada contra los derechos sexuales y reproductivos (Arguedas, 2020; Corrales, 2018, January 17).

De esta forma, la difusión del discurso de la «ideología de género» como reacción a los derechos sexuales y reproductivos presenta un conjunto de actores estrechamente vinculados: primero, la Iglesia católica y las iglesias evangélicas pentecostales y neopentecostales; segundo, organizaciones de la sociedad civil que se presentan como defensoras de valores morales tradicionales; tercero, actores políticos con fuertes vínculos con iglesias y agrupaciones conservadoras. ${ }^{2}$ En la medida en que más Estados han incorporado los derechos sexuales y reproductivos a sus marcos constitucionales y legales,

\footnotetext{
${ }^{2}$ Dadas las características de esta investigación, que busca analizar el panorama general de las protestas y las reacciones gubernamentales en siete países de América Latina, no se realizarán descripciones detalladas de los actores por país, solo se señalarán las similitudes clave que permiten identificar los patrones en los casos analizados.
} 
las acciones de las organizaciones conservadoras buscan incidir en la toma de decisiones políticas al interior de los Estados y en el impulso de agendas que bloqueen el avance de estos derechos a través de la participación política electoral y la presión legislativa. ${ }^{3}$

\section{La reactivación de las protestas contra la «ideología de género»}

Los antecedentes más importantes de la activación de la reacción conservadora a través de protestas masivas frente al avance institucional de los derechos sexuales y reproductivos se presentaron, por lo menos, desde 2010, especialmente en países como Argentina y Brasil, donde hubo un avance temprano en estas agendas. Por un lado, han sido muy analizados los conflictos que se dieron en el marco de la discusión de la ley que legalizó los matrimonios igualitarios en Argentina en 2010, conflictos que se traslaparon de manera más aguda en los diversos debates en torno al aborto, con un gran peso de argumentos basados en la bioética (Felitti, 2011). Por otro lado, en Brasil, luego del fallo del Consejo Nacional de Justicia que aprobó las bodas civiles entre personas del mismo sexo en mayo de 2013, se presentaron protestas masivas con la participación de miles de personas evangélicas y católicas en varias ciudades. De estas protestas destacaron la «Marcha por Jesús», encabezada por el alcalde de Río de Janeiro (BBC News, 2013, mayo 26) y la marcha convocada por el Movimiento Nacional de la Ciudadanía por la Vida en Brasilia, donde aproximadamente cuarenta mil participantes se opusieron al aborto y al matrimonio homosexual (Arias, 2013, junio 6).

Además de estos casos, otro antecedente significativo de las protestas y de la reacción conservadora se presentó en Costa Rica y Paraguay, en 2013 y 2014 respectivamente. En Costa Rica se dieron marchas y protestas multitudinarias, como las ocurridas contra el aborto, la fertilización in vitro y el matrimonio homosexual, movilizando un discurso «provida» y «profamilia» (Murillo, 2013, agosto 11). En Paraguay se presentaron protestas en junio de 2014 contra el aborto y el matrimonio igualitario, en el marco de la Asamblea General de la Organización de Estados Americanos (OEA) que se realizó en Asunción. Según los grupos conservadores, en esta Asamblea se impondría

\footnotetext{
${ }^{3}$ Como han mostrado Roman Kuhar y David Paternotte (2017) para el caso europeo, las acciones y políticas «antigénero» que se presentan en diferentes países tienen un claro carácter regional y global al compartir repertorios y símbolos, así como al establecer redes de cooperación. En América Latina, el Observatorio de Sexualidad y Política ha avanzado en la caracterización de estos actores en algunos casos (G\&PAL, s. f.).
} 
la Convención contra toda forma de Discriminación e Intolerancia —la cual Paraguay no había suscrito-, «permitiendo la imposición de la ideología de género como una verdad absoluta» (ABC Color, 2014, mayo 25). A diferencia de Brasil y Argentina, los casos de Paraguay y Costa Rica fueron dos de los de menor reconocimiento de derechos sexuales y reproductivos, lo cual evidencia la tendencia de la reacción conservadora bajo lógicas tanto reactivas — en los países donde estos derechos habían avanzado- como preventivas — donde los grupos privilegiados sentían amenazas ante un cambio legal-.

Ahora bien, es a partir de 2016 que se puede rastrear una clara estrategia de articulación y coordinación regional entre diferentes iglesias y organizaciones civiles en América Latina para impulsar protestas y acciones, retomando la centralidad del término «ideología de género». Por una parte, en Ciudad de México en 2016 se realizó la primera reunión continental de organizaciones civiles — de países como Colombia, México, El Salvador, Perú, Brasil— para crear el «Frente latinoamericano por el derecho a la vida y a la familia», expresando como uno de sus pilares del acuerdo el rechazo a la Organización de Naciones Unidas (ONU) y organizaciones internacionales y nacionales de derechos humanos que estarían impulsando «una ideología de género en detrimento de los valores de las sociedades» (Semana, 2016, septiembre 13).

Por otra parte, hacia finales de 2016 y principios de 2017 las redes de organizaciones conservadoras crearon el Congreso Iberoamericano por la Vida y la Familia (s. f.), a raíz de la Iniciativa Ciudadana por la Vida y la Familia —México, 2016-, como un movimiento para defender los derechos de las familias de Iberoamérica por medio de políticas públicas.

Por último, se dio un proceso de trabajo colectivo y asesoramiento entre políticos y políticas de diferentes países para impulsar campañas contra el matrimonio igualitario, la identidad de género y los manuales de educación sexual, centrándose en estrategias para movilizar a los padres de familia frente a las amenazas que implicarían los derechos como el matrimonio igualitario o la educación sexual, según sus concepciones morales (Biroli y Caminotti, 2020; Moragas, 2020; González et al., 2018). ${ }^{4}$

\footnotetext{
${ }^{4}$ Portales de investigación periodística como Transnacionales de la fe (s. f.) han documentado que existió una relación de colaboración y asesoría entre diversos actores políticos de países como Colombia y Perú para impulsar protestas contra la ideología de género, así como el impulso de este tipo de organizaciones por parte de agencias estadounidenses vinculadas con agendas ultraconservadoras contra el aborto y los derechos sexuales.
} 
La coordinación entre iglesias, organizaciones y políticos conservadores iniciada en 2016 le dio un nuevo carácter regional a la estrategia de reposicionamiento de la oposición a los derechos sexuales y reproductivos al interior de los Estados. De esta manera, en el cuadro 1 se identifican los principales episodios de protesta en Colombia, México, Ecuador, Perú, Paraguay, Bolivia y Panamá, convocados como oposición a la «ideología de género» y que incluyeron marchas masivas como principal repertorio de manifestación pública.

Cuadro 1. Principales episodios de marchas y protestas convocadas contra la «ideología de género», 2016-2018.

\begin{tabular}{|c|c|c|c|}
\hline País & $\begin{array}{c}\text { Fecha de las } \\
\text { marchas }\end{array}$ & Objetivo de reclamo & Actores principales \\
\hline Colombia & $10 / 08 / 2016$ & $\begin{array}{l}\text { Contra cartillas de educación } \\
\text { sexual que reconocían el } \\
\text { enfoque de género y contra la } \\
\text { ministra de Educación. }\end{array}$ & $\begin{array}{l}\text { Iglesia católica. } \\
\text { Organizaciones y grupos } \\
\text { evangélicos. } \\
\text { Políticos nacionales. } \\
\end{array}$ \\
\hline México & $24 / 09 / 2016$ & $\begin{array}{l}\text { Contra la reforma presentada } \\
\text { por el ejecutivo nacional que } \\
\text { homologaba derechos en el } \\
\text { ámbito estatal. }\end{array}$ & $\begin{array}{l}\text { Frente Nacional por la Familia. } \\
\text { Consejo Coordinador de } \\
\text { Movimientos por la Vida y la } \\
\text { Familia. } \\
\text { Iglesia católica; iglesias } \\
\text { evangélicas. }\end{array}$ \\
\hline \multirow[t]{2}{*}{ Ecuador } & $14 / 10 / 2017$ & $\begin{array}{l}\text { Oponerse a manuales con } \\
\text { inclusión de educación sexual } \\
\text { y perspectiva de género. }\end{array}$ & \multirow{2}{*}{$\begin{array}{l}\text { Grupos Profamilia. } \\
\text { Frente Nacional por la Familia. } \\
\text { Iglesia católica. } \\
\text { Iglesias evangélicas. }\end{array}$} \\
\hline & $28 / 07 / 2018$ & $\begin{array}{l}\text { Contra la Ley Orgánica para } \\
\text { la Erradicación de la Violencia } \\
\text { de Género contra las Mujeres. }\end{array}$ & \\
\hline \multirow[t]{2}{*}{ Perú } & $04 / 03 / 2017$ & $\begin{array}{l}\text { Oponerse a la inclusión de } \\
\text { manuales de educación sexual } \\
\text { en el currículo nacional de } \\
\text { educación básica. }\end{array}$ & \multirow{2}{*}{$\begin{array}{l}\text { Coordinadora Nacional Pro } \\
\text { Familia. } \\
\text { Grupos evangélicos. } \\
\text { Iglesia católica. } \\
\text { Colectivos de padres de familia. } \\
\text { Políticos nacionales (Fuerza } \\
\text { Popular). }\end{array}$} \\
\hline & $22 / 03 / 2015$ & $\begin{array}{l}\text { Contra proyecto de Ley unión } \\
\text { de parejas del mismo sexo. }\end{array}$ & \\
\hline \multirow[t]{3}{*}{ Panamá } & $13 / 07 / 2017$ & $\begin{array}{l}\text { Rechazo al proyecto de Ley } \\
61 \text { sobre salud y educación } \\
\text { sexual. }\end{array}$ & \multirow{3}{*}{$\begin{array}{l}\text { Alianza Evangélica. } \\
\text { Alianza Panameña por la Vida y } \\
\text { la Familia. } \\
\text { lglesia católica. }\end{array}$} \\
\hline & $13 / 07 / 2016$ & $\begin{array}{l}\text { Rechazo al matrimonio } \\
\text { igualitario }\end{array}$ & \\
\hline & 06/03/2018 & $\begin{array}{l}\text { Contra el matrimonio } \\
\text { igualitario y la opinión } \\
\text { consultiva de la CIDH. }\end{array}$ & \\
\hline
\end{tabular}


Cuadro 1. (Continuación)

\begin{tabular}{|c|c|c|c|}
\hline País & $\begin{array}{c}\text { Fecha de las } \\
\text { marchas }\end{array}$ & Objetivo de reclamo & Actores principales \\
\hline \multirow[t]{3}{*}{ Paraguay } & $30 / 09 / 2017$ & \multirow{2}{*}{$\begin{array}{l}\text { Contra cartillas de educación } \\
\text { sexual y de género. }\end{array}$} & \multirow{3}{*}{$\begin{array}{l}\text { Grupos de Padres de Familia. } \\
\text { Colectivos cristianos. } \\
\text { Iglesia católica. } \\
\text { Paraguay Defiende la Vida y la } \\
\text { Familia. }\end{array}$} \\
\hline & 05/10/2017 & & \\
\hline & 062017 & $\begin{array}{l}\text { Oponerse a la Resolución } \\
\text { de Igualdad e Identidad } \\
\text { de Género en el marco de } \\
\text { la reunión de la OEA en } \\
\text { Asunción. }\end{array}$ & \\
\hline \multirow[t]{2}{*}{ Bolivia } & $22 / 06 / 2016$ & $\begin{array}{l}\text { Contra la Ley } 807 \text { de } \\
\text { Identidad de Género. }\end{array}$ & \multirow{2}{*}{$\begin{array}{l}\text { Plataforma por la vida y la } \\
\text { familia. } \\
\text { Conferencia Episcopal } \\
\text { Boliviana. } \\
\text { Iglesias Evangélicas Unidas. }\end{array}$} \\
\hline & $13 / 07 / 2018$ & $\begin{array}{l}\text { Contra material educativo } \\
\text { socializado por la ONG Save } \\
\text { the Children. }\end{array}$ & \\
\hline
\end{tabular}

Fuente: elaboración propia a partir de información de prensa.

Sin diferencias en los casos donde las protestas fueron reactivas o preventivas, se evidencia que la reacción tuvo tres rasgos comunes: en primer lugar, las marchas se presentaron como respuestas-reacciones al intento de reconocimiento de derechos - como el matrimonio igualitario y políticas de identidad de género- o contra la implementación de políticas públicas en materia de derechos sexuales y reproductivos, especialmente políticas en materia de educación sexual que incluían contenidos escolares de acuerdo con los parámetros establecidos por organismos internacionales. Las políticas educativas son una demanda nodal de los movimientos feministas y LGBT por promover transformaciones culturales de fondo, y cobran mayor relevancia en un continente donde se presentan cifras muy elevadas de feminicidios, violencia de género y homofóbica. Igualmente, las disputas por los contenidos escolares en torno a la educación sexual y la separación de las creencias religiosas y la educación pública implican fuertes resistencias a los principios del Estado laico (Díaz, 2019).

En segundo lugar, todas las convocatorias a las marchas se hicieron en oposición a lo que denominan como «ideología de género», aglutinando 
bajo este objetivo consignas como, «Con mis hijos no te metas», «A mis hijos los educo yo», «Es biología no ideología». La estética de las protestas fue compartida, apelando a los colores azul y rosa como representación de las «asignaciones naturales» de lo masculino y lo femenino. Igualmente, en todos los casos la mediación de las protestas pasó tanto por las convocatorias directas en las iglesias, a través del contacto físico, como también por medio de las redes sociodigitales, las cuales desempeñaron un papel central en la difusión de noticias para «alarmar»—como cadenas de WhatsAap, grupos de Facebook o portales de noticias falsas-y para conectar a las personas. Si bien, como ya se explicó, el discurso de la «ideología de género» ha sido usado por diversos sectores conservadores, por lo menos desde la década de 1990, en esta ocasión se presenta una difusión de consignas de identificación de las causas, donde se asocia el reconocimiento de los derechos sexuales y reproductivos como una afectación directa a los derechos de los padres de familia y de los niños, justificando la realización de marchas masivas con presencia de diversos sectores religiosos sin precedentes en cada uno de los casos.

Finalmente, todos los eventos de protesta fueron convocados por organizaciones vinculadas a las iglesias católicas y evangélicas, junto con asociaciones de padres de familia, las cuales tienen fuertes vínculos con actores institucionales y capacidad de incidencia y cabildeo. En todos los países hicieron presencia pública en las marchas desde líderes de las iglesias, políticos de diferentes partidos, así como representantes de asociaciones civiles que reproducen los símbolos y mensajes religiosos. Además de esta clara característica, en la que hay una similitud de los actores convocantes, resalta el hecho de que en todos los casos los actores se presentan como redes, plataformas o asociaciones en defensa de «la vida y la familia», compartiendo incluso los nombres de las organizaciones más importantes, como en el caso del Frente Nacional por la Familia en Ecuador y México.

\section{La resonancia pública de las protestas}

La convocatoria común a realizar manifestaciones contra la «ideología de género» refleja una estrategia de reposicionamiento de un término que históricamente ha sido utilizado por las iglesias, esta vez, 
con el liderazgo de organizaciones civiles en relación con los contextos políticos particulares de los diferentes países de la región. En tal sentido, además de los mensajes enviados a los gobiernos a partir de las acciones de protesta, la difusión de marcos de demanda y posicionamiento discursivo se puede evidenciar a través de los indicadores de atención del público (Cammaerts, 2018). Un indicador aproximado de la resonancia e interés generado por las demandas y discursos de los movimientos conservadores se puede encontrar en las búsquedas en Internet que las personas realizan sobre un tema o término en específico (Bennett, Segerberg y Yang, 2018). Para ello, utilizando la herramienta Google Trends, se identificó el total de búsquedas realizadas del término «ideología de género» en los países seleccionados, con el fin de identificar un indicador aproximado del interés generado en torno al marco de las demandas. Este indicador, además, permite visualizar la atención del público en términos temporales y de intensidad, pues refleja un agregado de «interés» dentro de un rango de 0 a 100, donde 100 indica la máxima y 0 la mínima popularidad de un término dentro del periodo analizado, es decir, no presenta búsquedas totales sino comparaciones de interés en momentos específicos.

La búsqueda se realizó para el periodo 2013-2019 para tener un control temporal de los resultados, es decir, observando si previamente a la coyuntura de las protestas analizadas se habían presentado indicadores significativos de interés sobre el término «ideología de género» (véanse gráficas 1-7).

Como se observa en las gráficas 1-7, las búsquedas en Google del término «ideología de género» en Colombia, México, Ecuador, Paraguay, Panamá, Bolivia y Perú eran básicamente inexistentes antes de las escenificaciones de protesta. En todos los casos se identifican los mayores picos de búsquedas del término «ideología de género» durante las primeras marchas masivas convocadas por las organizaciones conservadoras, lo que representa un claro y significativo aumento en la atención del público sobre un tema que previamente no generaba interés. En otras palabras, los resultados reflejan que las estrategias de movilización y protesta lideradas en todos los países por las organizaciones conservadores están correlacionadas con un proceso de difusión y reposicionamiento de una idea, la de la «ideología de género», que previamente no generaba atención. 
La (re)irrupción del discurso de la «ideología de género» en América Latina...

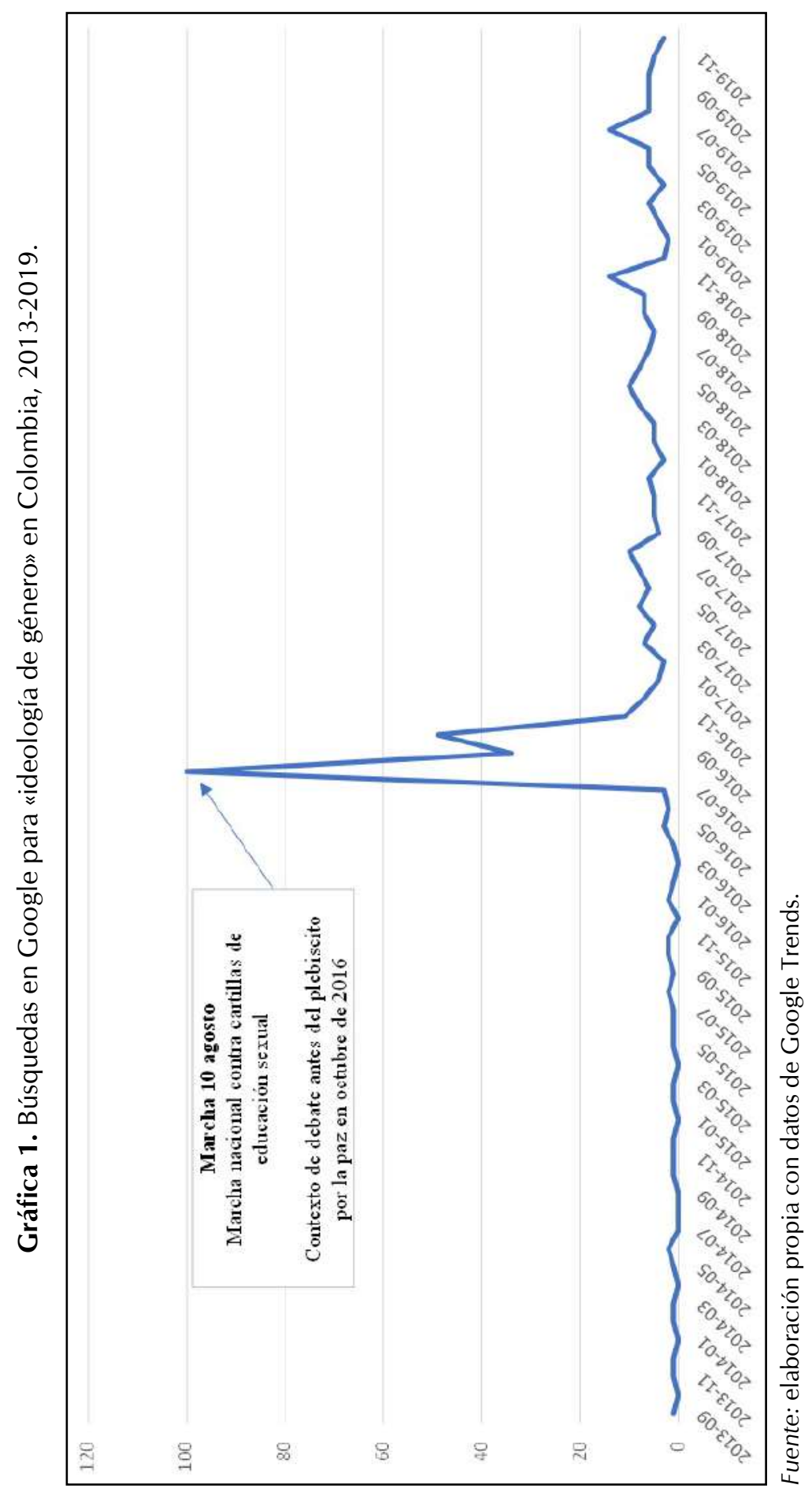


[160]

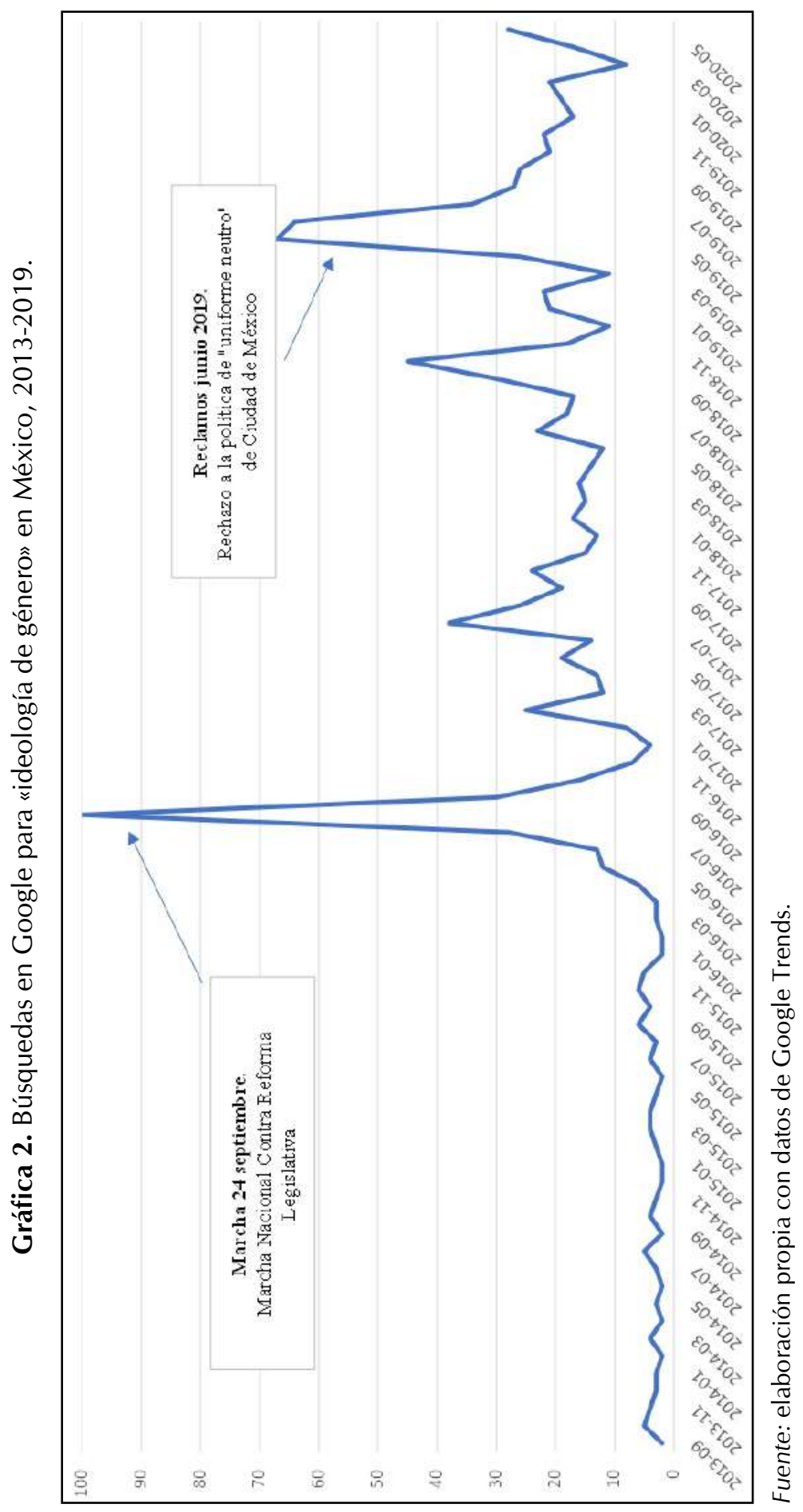


La (re)irrupción del discurso de la «ideología de género» en América Latina...

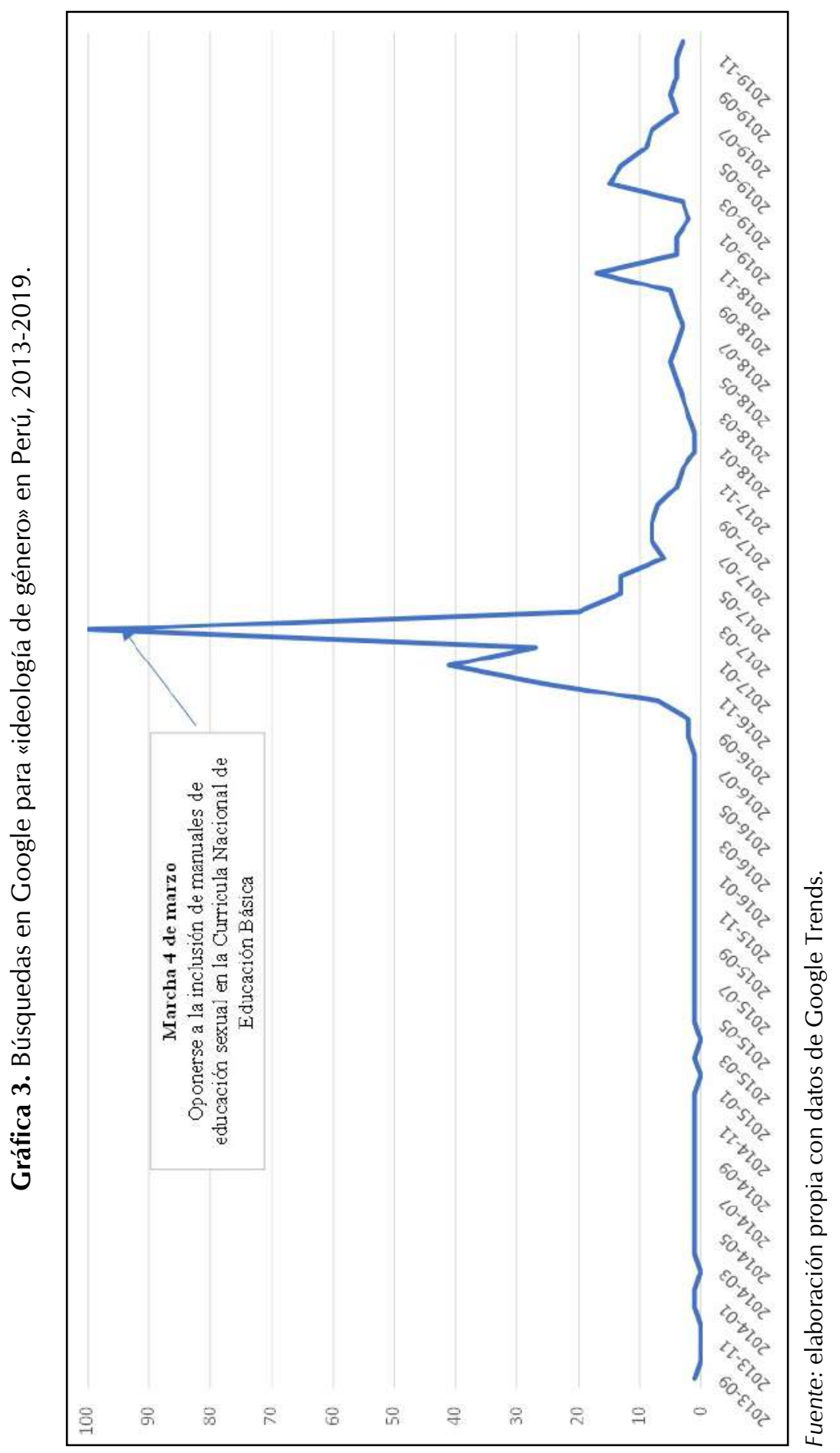


[162 ]

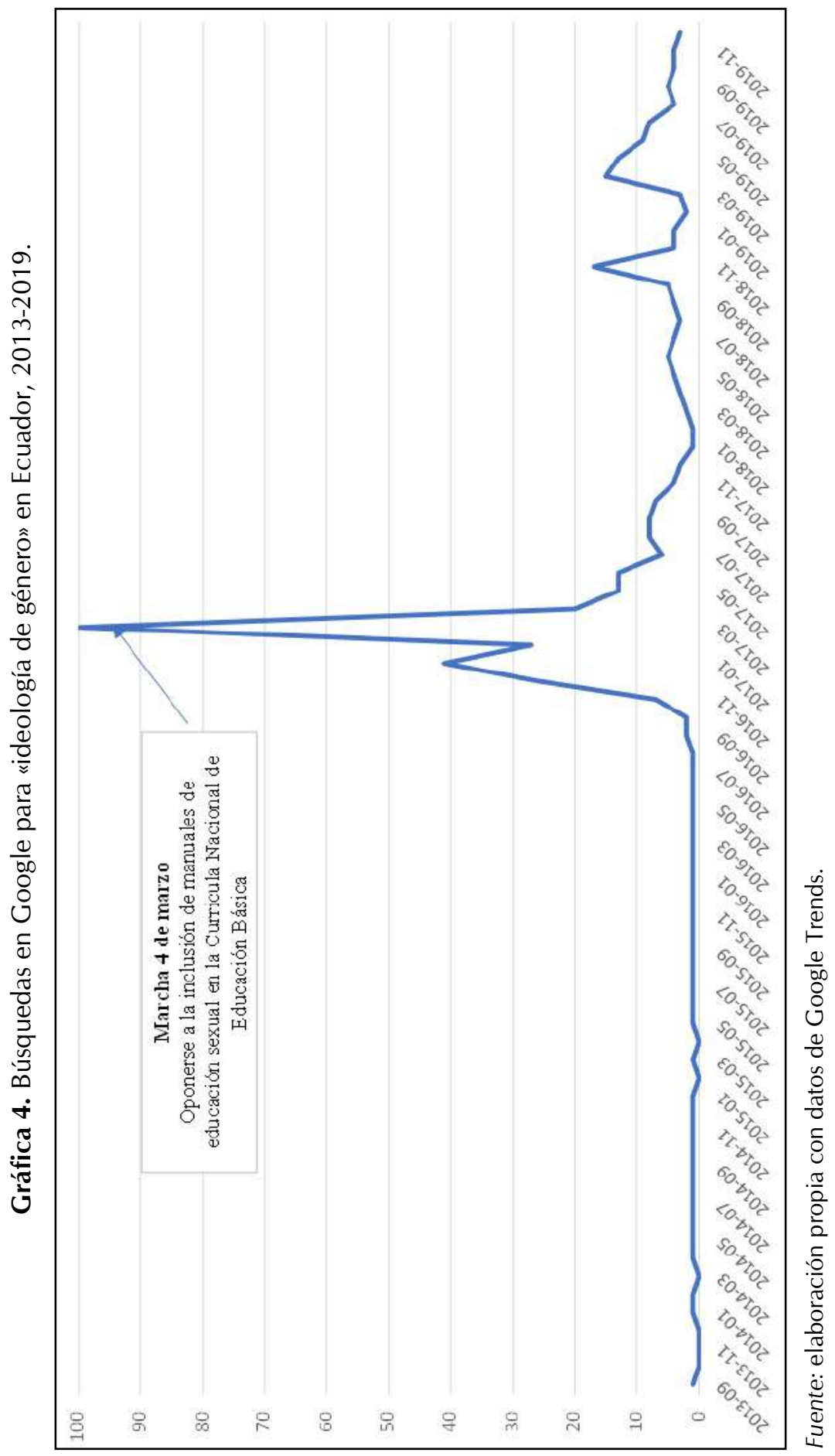


La (re)irrupción del discurso de la «ideología de género» en América Latina...

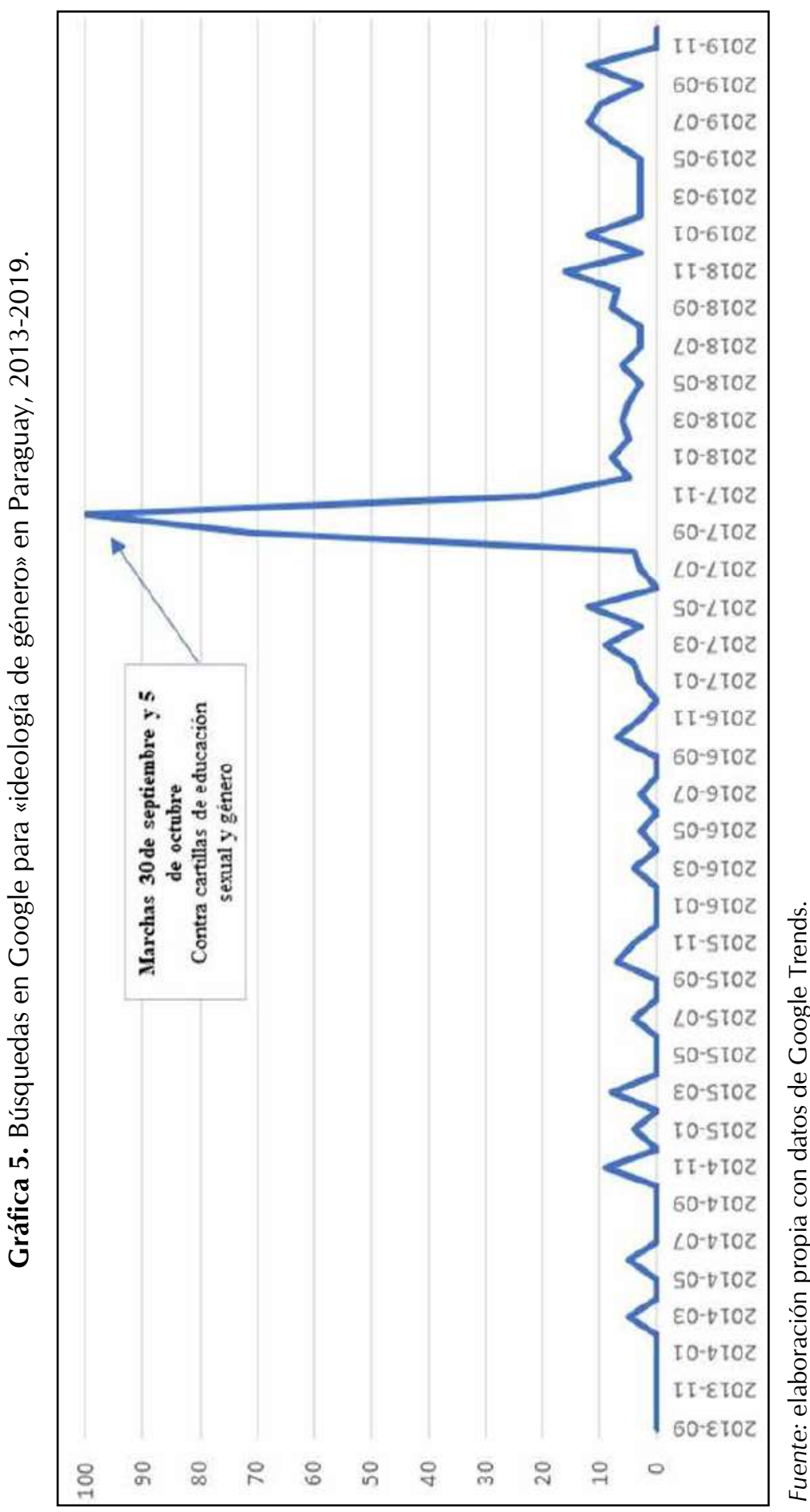




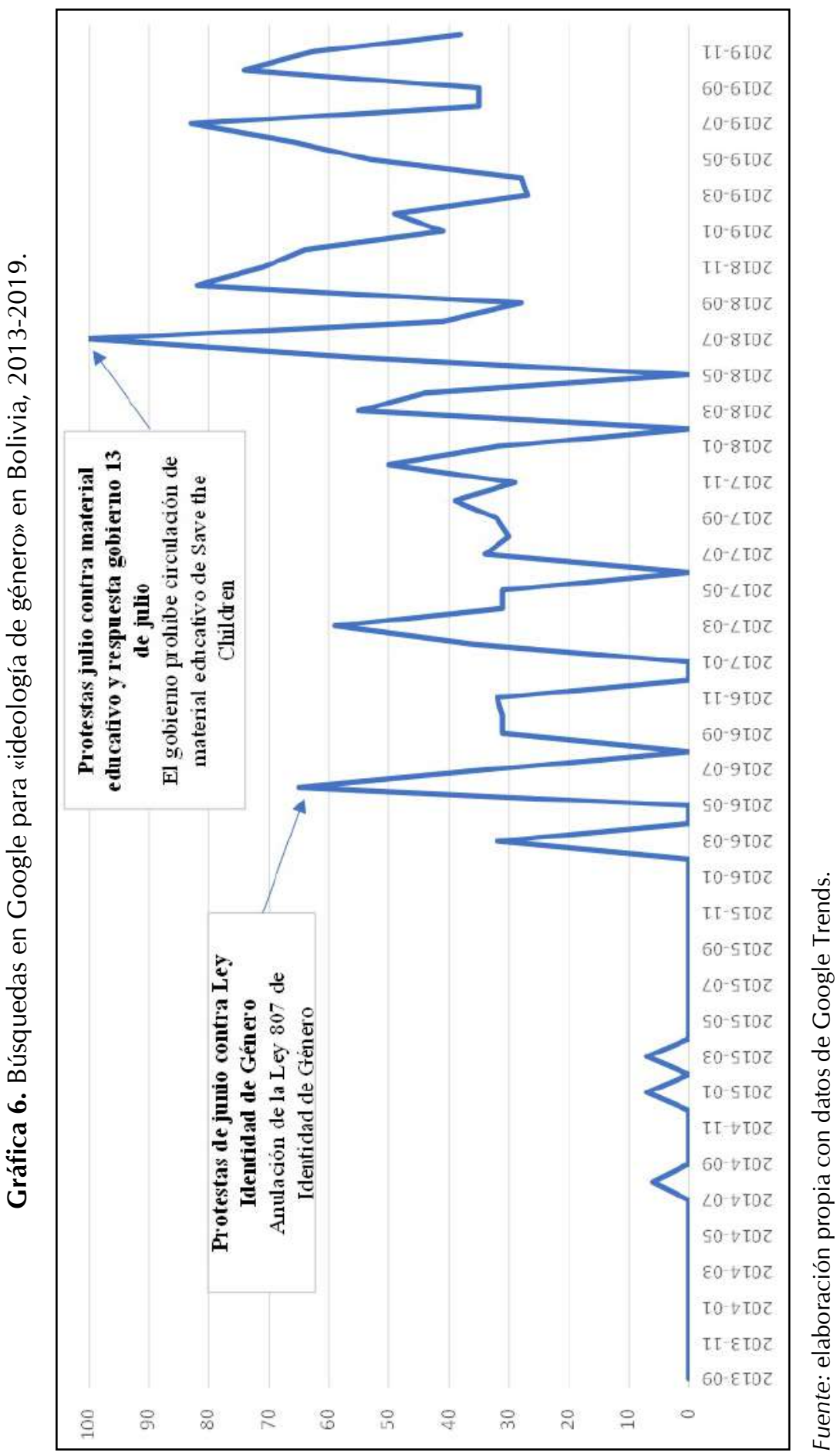


La (re)irrupción del discurso de la «ideología de género» en América Latina...

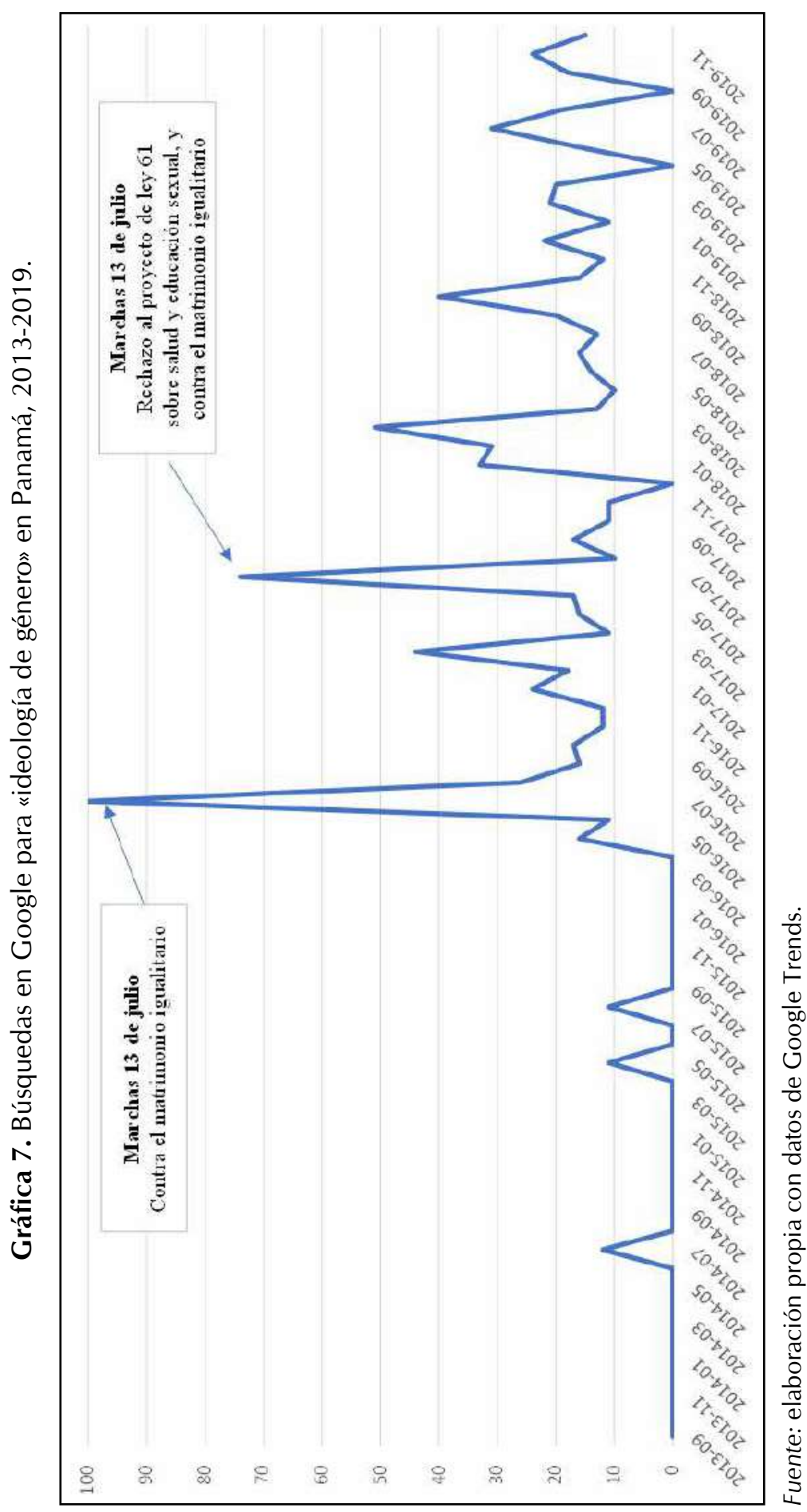


Este indicador es significativo ya que, a pesar de que la genealogía del discurso de la «ideología de género» se remonta hasta las décadas de 1980 y de 1990, en los siete casos analizados dicho discurso irrumpe en el interés ciudadano asociado a los momentos de protesta y manifestación de la reacción conservadora frente a políticas en coyunturas particulares.

En los casos de Panamá, Bolivia, Ecuador y México se encontró que el interés por el término presentó diversos picos, asociados a varias manifestaciones masivas que impulsaron las organizaciones de la reacción conservadora para oponerse a políticas gubernamentales de reconocimiento de derechos o implementación de políticas de educación sexual. De manera contraria, en Colombia, Perú y Paraguay los indicadores muestran que, tras los mayores picos de interés, este se mantuvo con una constante no mayor de 20 puntos, lo que podría indicar que los principales conflictos asociados a las demandas conservadoras se concentraron en un periodo corto de tiempo. En todos los casos, una vez iniciadas las estrategias de demanda contra los derechos sexuales y reproductivos el marco de la «ideología de género» quedó establecido dentro de la atención de las personas, lo que junto con los seguimientos noticiosos indican una irrupción de la idea en la esfera pública.

\section{[166] 5. De las protestas a las respuestas gubernamentales}

Las protestas y su resonancia pública estaban directamente orientadas a presionar e incidir sobre los gobiernos en torno a las decisiones políticas tomadas en estas materias. Los movimientos conservadores utilizan el activismo callejero como un mecanismo de presión, especialmente basado en la construcción de un mensaje de «masividad» en las marchas como amenaza para «elevar los costos políticos» del reconocimiento de los derechos sexuales (López, 2017). Para identificar la relación y efectividad de los mensajes y la presión ejercida por las protestas sobre los gobiernos, es necesario descomponer los objetivos de los reclamos y la manera en que los gobiernos respondieron frente a la presión.

Los primeros episodios de marchas y protestas en 2016 se presentaron en Colombia, Panamá, México y Bolivia, marcando el auge de la reacción conservadora que se extendió en todo el continente. En Colombia, las protestas se dieron como reacción a la elaboración de cartillas de educación sexual por parte del Gobierno nacional y Naciones Unidas — como exigencia de la Sentencia T-478 de 2015 de la Corte Constitucional-, las cuales reconocían el enfoque de género y buscaban crear ambientes escolares libres 
de discriminación (López, 2017). En Panamá, las reacciones se agudizaron desde mediados de 2016, cuando el gobierno nacional discutía el Proyecto de Ley 61 sobre Salud y Educación Sexual, además que proponía la creación de la Dirección Nacional de Género y Desarrollo Humano del Ministerio de Educación (El Siglo, 2016, julio 13). ${ }^{5}$ En México se dieron protestas masivas luego de que el Ejecutivo presentó en mayo de 2016 un paquete de reformas al Congreso de la Unión, en el que se incluía la legalización del matrimonio igualitario, la adopción por parte de parejas del mismo sexo, la posibilidad de realizar cambios de sexo en los documentos de identidad y la promoción de la tolerancia de la diversidad sexual (Rodríguez, 2016, mayo 19).

En los tres casos, la respuesta inmediata de los gobiernos fue la de «calmar» las protestas, comprometiéndose con la «no inclusión de la ideología de género» en los manuales escolares o con una «discusión más profunda de las reformas», derivando en la no aplicación de las políticas o cambios propuestos. En Colombia, el entonces presidente Juan Manuel Santos se reunió con jerarcas de la Iglesia católica para asegurarles que no habría ninguna implantación de la ideología de género y que las cartillas no iban a ser publicadas, constituyéndose esta decisión en una importante victoria de la acción colectiva conservadora (Semana, 2016, agosto 11). Este triunfo se sumó a la renuncia de la entonces ministra de Educación —-declarada abiertamente homosexual y objeto de los ataques conservadores- y a un protagonismo mediático de las iglesias evangélicas que se oponían al plebiscito por la paz de octubre de $2016 .{ }^{6}$

En Panamá, el presidente de la Asamblea Nacional se reunió con las organizaciones conservadoras y les garantizó que dicho proyecto regresaría a la Comisión de Salud del Congreso, incluyendo las demandas de dichos sectores. Hasta la fecha, en Panamá no hay una Ley Nacional de Educación Sexual, hecho denunciado en diversas ocasiones por el Comité de los

\footnotetext{
${ }^{5}$ Iguales protestas se presentaron en Panamá en junio de 2017 cuando la Corte Suprema de Justicia acumuló dos demandas de inconstitucionalidad contra el artículo 26 del Código de la Familia, que define al matrimonio como la unión entre un hombre y una mujer, y el subsiguiente artículo 35, que literalmente prohíbe el matrimonio entre parejas del mismo sexo (Díaz, 2017, junio 14). Finalmente, la Suprema Corte declaró constitucional los artículos del código de familia que definen al matrimonio como la unión entre hombre y mujer.

${ }^{6}$ Las iglesias tenían su propia agenda de crítica a los acuerdos pues, según ellos, estos reproducían la ideología de género y buscaban acabar con la familia tradicional. El activismo electoral impulsado por estas iglesias movilizó un estimado de quinientos mil fieles, los cuales terminaron siendo decisivos en el estrecho margen del triunfo del No en el plebiscito del 2 de octubre de $2016-0,5 \%$ de los votos(López, 2017).
} 
Derechos del Niño de Naciones Unidas (Cardiel, 2018, febrero 8). En México, la propuesta de reforma del Ejecutivo fue archivada en el Congreso mexicano e incluso en dicha coyuntura se presentó un llamado desde las tribunas de las iglesias a no votar por el partido de gobierno - Partido Revolucionario Institucional (PRI) — en las elecciones subnacionales, razón por la cual los jerarcas de la iglesia terminaron apropiándose de la victoria del conservador Partido de Acción Nacional en los comicios estatales de 2016 (López, 2017).

Por su parte, en Bolivia el avance en el reconocimiento de los derechos sexuales y reproductivos ha sido lento y contradictorio. Si bien el país andino es de los pocos que constitucionalmente prohíbe la discriminación por orientación sexual, tiene leyes que prohíben a las personas homosexuales donar sangre, prestar servicio militar, acceder al matrimonio igualitario y la adopción por parte de parejas del mismo sexo. Precisamente, esta contradicción se vio reflejada en las reacciones que generó la Ley 806 de Identidad de Género de 2016, la cual permite a personas transexuales y transgénero el cambio de nombre, sexo e imagen de su documento de identidad. Luego de la aprobación de esta Ley, grupos conservadores liderados por la Iglesia católica y pastores cristianos, a través de la Plataforma por la Vida y la Familia, convocaron a una masiva marcha en todo el país en defensa de la cultura familiar boliviana. Bajo un discurso nacionalista y que apelaba a las costumbres indígenas, la reacción conservadora promovió la resistencia a la Ley a través de una acción de inconstitucionalidad ante el Tribunal Constitucional, solicitando desconocerla. En noviembre de 2017 el Tribunal Constitucional se pronunció y anuló una supuesta contradicción constitucional al señalar que la población trans no puede adoptar, casarse o exigir paridad de género, ya que estos derechos no le han sido reconocidos, a pesar de que una persona que cambia de género es reconocida oficialmente con su nuevo género (Escudero, 2017, noviembre 21).

En 2017 continuó en aumento la reacción conservadora en el ámbito regional y se sumaron fuertes episodios de protesta en Ecuador, Perú y Paraguay —además de protestas en Brasil, Costa Rica y Uruguay que no se analizarán aquí-. En todos los países, la lógica de la reacción continuó siendo la oposición a políticas de educación sexual que iban a implementar los gobiernos. Nuevamente, en los tres casos la lógica de la respuesta oficial fue similar, ceder ante la presión y desistir de su aplicación para disminuir los supuestos costos políticos que estas medidas podrían traer. 
En el caso de Ecuador, las marchas de octubre de 2017 se opusieron al Código Orgánico de la Salud y al proyecto de Ley Orgánica para la Erradicación de la Violencia de Género contra las Mujeres que tramitaba el nuevo gobierno de Lenin Moreno. Los grupos conservadores cuestionaban, entre otras, la inclusión de la categoría de género, argumentando que esta promovía la homosexualidad de los niños (El Comercio, 2017, octubre 13; La República, 2017, octubre 14). Como respuesta gubernamental, el 16 de octubre se dio a conocer que el Proyecto de Ley Orgánica había sido modificado, específicamente, se eliminaron las expresiones «autodeterminación sexual y de género», «identidad de género», «orientación sexual» y «mujeres de orientaciones sexuales e identidades de género diversas», transformando sustancialmente los sujetos que eran protegidos por la ley y aceptando los reclamos conservadores.

En Perú, las protestas se opusieron a la propuesta de manual de currículo escolar emitida por el gobierno de Pedro Kuczynski, que había llegado a la Presidencia con una abierta agenda de reconocimiento de derechos de las mujeres (El País, 2017, marzo 3; La República, 2017, marzo 3). En un influyente comunicado a principios de 2017, el Episcopado Católico Peruano señaló que la inclusión de nociones como la «identidad de género» contravenía la Constitución, vulnerando además el derecho de los padres de familia de participar en la definición de los parámetros de la educación pública que reciban sus hijos. ${ }^{7}$ Como consecuencia de la presión, en agosto de 2017, y tras una demanda de acción popular interpuesta por el Colectivo Padres en Acción, la Corte Superior de Justicia de Lima resolvió anular el contenido del Currículo Nacional, ordenando eliminar el acápite II de la guía, donde se afirmaba: «si bien aquello que consideramos femenino o masculino se basa en una diferencia biológica sexual, estas son nociones que vamos construyendo día a día, en nuestras interacciones» (Olayo, 2017, agosto 28). El 24 de noviembre de 2017 el gobierno peruano dispuso la aplicación del Diseño Curricular Nacional 2009 en el Diario Oficial, currículo en el que se incluyen las nociones de igualdad de género.

En Paraguay, además del nulo reconocimiento de derechos sexuales y reproductivos ya mencionado, en 2017 circuló un falso audio e imágenes en redes sociales en las que se aseguraba que el gobierno estaba dando

\footnotetext{
${ }^{7}$ Las organizaciones conservadoras venían articulándose desde, por lo menos, 2016 bajo la campaña «Con Mis Hijos No Te Metas», la cual encontró un espacio importante de circulación y difusión en redes sociodigitales (Meneses, 2019).
} 
instrucciones a los maestros de las escuelas públicas, por medio de manuales de educación, para promover la homosexualidad y el aborto, lo que impulsó protestas y la exigencia de destitución del Ministro de Educación acusándolo de incitar a la ideología de género. La respuesta del gobierno fue contundente, ya que el ministro de Educación y Ciencias de Paraguay emitió una resolución prohibiendo el uso y difusión de materiales didácticos «que hagan alusión a la ideología de género» en todas las escuelas públicas del país, además de liderar «una cruzada oficial» contra la ideología de género, haciendo incluso llamados a «quemar los manuales en la plaza pública» (ABC Color, 2017, septiembre 18; 51. Carneri, 2017, diciembre 27).

Cuadro 2. Principales respuestas gubernamentales frente a las protestas contra la «ideología de género».

\begin{tabular}{|l|l|}
\hline \multicolumn{1}{|c|}{ País } & \multicolumn{1}{c|}{ Respuesta gubernamental } \\
\hline Colombia & $\begin{array}{l}\text { Eliminación de las cartillas de educación y compromiso del presidente de } \\
\text { no difundir la «ideología de género». Renuncia de la ministra de Educación. } \\
\text { Protagonismo en el triunfo del No en el plebiscito por la paz. }\end{array}$ \\
\hline México & $\begin{array}{l}\text { La reforma federal por los derechos LGBT se archivó en el Congreso de la } \\
\text { Unión. Incidencia en elecciones locales y estatales. Bloqueo despenalización } \\
\text { del aborto en el ámbito subnacional. }\end{array}$ \\
\hline Ecuador & $\begin{array}{l}\text { El Gobierno modificó el proyecto de ley eliminando la orientación sexual e } \\
\text { identidad de género como principios de protección. El matrimonio igualitario } \\
\text { fue reconocido vía fallo del tribunal constitucional. }\end{array}$ \\
\hline Perú & $\begin{array}{l}\text { La Corte Superior de Justicia de Lima anuló el contenido del currículo nacional, } \\
\text { especialmente lo referido a la construcción de la identidad de género. EI } \\
\text { Gobierno peruano retiró el Manual Educativo. }\end{array}$ \\
\hline Panamá & $\begin{array}{l}\text { La Suprema Corte de Justicia declaró constitucional la restricción del matrimonio } \\
\text { a la unión entre hombre y mujer. Panamá aún no cuenta con Ley de Educación } \\
\text { Sexual Integral. Eliminación de la Dirección Nacional de Género y Desarrollo } \\
\text { Humano dentro del Ministerio de Educación. }\end{array}$ \\
\hline Paraguay & $\begin{array}{l}\text { El ministro de Educación y Ciencias prohibió, por resolución, «la enseñanza } \\
\text { de la ideología de género». El Gobierno paraguayo ha tenido una posición de } \\
\text { rechazo a la inclusión de derechos LGBT en el marco de la OEA. }\end{array}$ \\
\hline Bolivia & $\begin{array}{l}\text { Se restringieron derechos como el matrimonio y adopción de parejas del mismo } \\
\text { sexo permitidos, en principio, en la Ley de Identidad de Género. El Gobierno } \\
\text { prohíbe la circulación del material educativo en las escuelas del país. }\end{array}$ \\
\hline
\end{tabular}

Fuente: elaboración propia a partir de información de prensa.

Como se resume en el cuadro 2, las protestas de las organizaciones conservadoras, además de generar un efecto de interés del público y de los medios en torno a sus demandas aglutinadas en la idea de la «ideología de 
género», tuvieron significativos efectos en las respuestas gubernamentales. En Colombia, Ecuador, Paraguay, Panamá, Perú y Bolivia las protestas y presiones institucionales lograron limitar la implementación de políticas públicas en materia de derechos sexuales, principalmente, las referidas a los manuales de educación sexual, constituyéndose en resistencias efectivas con consecuencias materiales frente a los derechos. En casos como Paraguay, Panamá, Bolivia y Perú, donde los derechos sexuales y reproductivos no presentan avances significativos, la reacción conservadora se impuso como estrategia preventiva para resistir el reconocimiento de derechos como el matrimonio igualitario y la adopción homoparental, haciendo eco de sus demandas contra las políticas de educación en la materia.

El vínculo entre las protestas, la creciente irrupción pública del término «ideología de género» y los resultados de bloqueo impulsados por la reacción se evidencian en el tipo de respuestas gubernamentales. Cuando los gobiernos en Colombia, Panamá, Perú, Paraguay y Bolivia ofrecieron conferencias públicas para «tranquilizar» a la población y revertir las decisiones tomadas, aseguraron que no estaban «impulsando la ideología de género», reconociendo de esta manera la resonancia que tenía este marco discursivo y encuadrando su respuesta acorde a las demandas de los movimientos conservadores. Igualmente, cuando los gobiernos de México y Perú cedieron ante la presión y revirtieron las políticas propuestas haciendo llamados a una discusión nacional sobre el tema, enviaron un mensaje de reconocimiento del descontento movilizado por los grupos conservadores, anteponiendo los posibles costos políticos a su obligación de garantizar derechos. En la medida que los gobiernos nunca se orientaron a cuestionar la existencia misma de este aparato discursivo, sus respuestas enviaron el mensaje de que efectivamente el reconocimiento de derechos humanos y la implementación de políticas de educación sexual podrían responder a esta construcción discursiva denominada «ideología de género».

\section{Conclusiones}

Más allá de la dimensión religiosa de las respuestas conservadoras y su abierto carácter anti políticas de género señalado por la literatura, en este artículo se analizó la relación entre las estrategias políticas seguidas por los actores conservadores, la resonancia pública de sus ideas y la incidencia lograda en los procesos políticos. Uno de los principales aportes de este trabajo fue resaltar que la reacción conservadora ha tenido un efecto de difusión y 
reposicionamiento discursivo del término «ideología de género», asociado a un patrón de escenificación pública en marchas masivas que se presentaron con características similares en los siete casos analizados. Dicha resonancia se identifica, entre otros, en la renovada atención del público sobre el término «ideología de género» y la forma como este fue retomado por los diferentes gobiernos para dar respuesta a las demandas de la reacción conservadora.

Entre 2016 y 2018 se presentó una coyuntura de mayor coordinación regional entre organizaciones conservadoras, con estrategias de reacción tanto reactivas como preventivas. Durante este periodo las reacciones de las organizaciones conservadoras tuvieron como efectos concretos la limitación de políticas de educación sexual en Colombia, México, Perú, Paraguay, Panamá y Ecuador, así como la declinación de reformas legales para la formalización de los derechos en Perú, Bolivia, Panamá y México. Esta capacidad de incidencia política representa un límite y retroceso a la socialización de los derechos, al mismo tiempo que una amenaza latente de discriminación e intolerancia legitimada desde los gobiernos que ceden a la presión.

El principal recurso de la reacción conservadora en las calles es el mensaje de masividad que las marchas envían a los gobiernos, reforzado

[172] por la resonancia adquirida por el discurso de la «ideología de género». A pesar de que este discurso contradice los principios de división entre ética pública, religión y Estado — los cuales definen el Estado laico-, los líderes de los Ejecutivos expresaron en todos los casos su disposición a oponerse al avance de la «ideología de género». Esta relación entre protestas, atención del público y las respuestas gubernamentales quedó reflejada en la forma como los diferentes gobiernos enviaron mensajes de «calma», restringiendo y limitando las posibilidades de avance en el reconocimiento y disfrute de los derechos sexuales y reproductivos. El fortalecimiento político de los grupos aglutinados alrededor de la reacción a los derechos sexuales y reproductivos se consolida como una seria amenaza a fundamentos básicos la democracia, como son la inclusión, la igualdad y la garantía de los derechos humanos.

\section{Referencias bibliográficas}

1. ABC Color. (2014, mayo 25). Promueven manifestación contra la ideología de género y el aborto. https://www.abc.com.py/edicion-impresa/politica/promuevenmanifestacion-contra-la-ideologia-de-genero-y-el-aborto-1248561.html 
2. ABC Color. (2017, septiembre 18). La regla para el MEC: «papá, mamá e hijitos». https://www.abc.com.py/nacionales/mec-es-claro-a-favor-de-papa-mama-ehijitos-1632996.html

3. Arguedas, Gabriela. (2020). «Ideología de género», lo "post-secular», el fundamentalismo neopentecostal y el neointegrismo católico: La vocación antidemocrática. En: Corrëa, Sonia (ed.). Políticas antigénero en América Latina: Estudios de caso (pp. 11-35). Río de Janeiro: Observatorio de Sexualidad y Política.

4. Arias, Juan. (2013, junio 6). Los evangélicos protestan en Brasilia contra el aborto y el activismo gay. El País. https://elpais.com/sociedad/2013/06/06/ actualidad/1370490150_083654.html

5. Bárcenas, Karina. (2018). Pánico moral y de género en México y Brasil: Rituales jurídicos y sociales de la política evangélica para deshabilitar los principios de un estado laico. Religião \& Sociedade, 38 (2), pp. 85-118. https://doi.org/10.1590/010085872018v38n2cap03

6. BBC News. (2013, mayo 26). Miles marchan contra matrimonio homosexual en Brasil. https://www.bbc.com/mundo/ultimas_noticias/2013/05/130525_ultnot_ brasil_matrimonio_homosexual_rio_lav

7. Benford, Robert \& Snow, David. (2000). Framing Processes and Social Movements: An Overview and Assessment. Annual Review of Sociology, 26 (1), pp. 611-639. https://doi.org/10.1146/annurev.soc.26.1.611

8. Bennett, Lance; Segerberg, Alexandra \& Yang, Yunkang. (2018). The Strength of Peripheral Networks: Negotiating Attention and Meaning in Complex Media Ecologies. Journal of Communication, 68 (4), pp. 659-684. https://doi.org/10.1093/ joc/jqy032

9. Biroli, Flávia \& Caminotti, Mariana. (2020). The Conservative Backlash against Gender in Latin America. Politics \& Gender, 16 (1). https://doi.org/10.1017/ S1743923X20000045

10. Bob, Clifford. (2012). The Global Right Wing and the Clash of World Politics. Cambridge: Cambridge University. https://doi.org/10.1017/CBO9781139031042

11. Cammaerts, Bart. (2018). The Circulation of Anti-Austerity Protest. London: Palagrave Macmillan. https://doi.org/10.1007/978-3-319-70123-3

12. Cardiel, Victoria Isabel. (2018, febrero 8). ONU urge a Panamá que apruebe ley de educación sexual integral. La Prensa. https://www.prensa.com/mundo/ONUPanama-apruebe-educacion-integral_0_4959254027.html

13. Carnac, Romain. (2020). Imaginary Enemy, Real Wounds: CounterMovements, "Gender Theory», and the French Catholic Church. Social Movement Studies, 19 (1), pp. 63-81. https://doi.org/10.1080/14742837.2019.1708307

14. Carneri, Santi. (2017, diciembre 27). Paraguay lanza una cruzada contra la «ideología de género». El País. https:/elpais.com/internacional/2017/12/26/ america/1514302715_812007.html 
15. Congreso Iberoamericano por la Vida y la Familia. (s. f.). Inicio. http:// congresoiberoamericanoporlavidaylafamilia.org/

16. Corrales, Javier. (2018, January 17). A Perfect Marriage: Evangelicals and Conservatives in Latin America. The New York Times. https://www.nytimes. com/2018/01/17/opinion/evangelicals-politics-latin-america.html

17. Dancy, Geoff \& Sikkink, Kathryn. (2017). Human Rights Data, Processes, and Outcomes: How Recent Research Points to a Better Future. En: Hopgood, Stephhen; Snyder, Jack y Vinjamuri, Leslie (es.). Human Rights Futures (pp. 24-59). Cambridge: Cambridge University. https://doi.org/10.1017/9781108147767.002

18. Díaz, Armando. (2019). Laicidad y educación sexual. México, D. F.: Instituto de Investigaciones Jurídicas-UNAM.

19. Díaz, Juan Manuel. (2017, junio 14). Corte acumula demandas a favor del matrimonio igualitario; el ponente será Luis Fábrega. La Prensa. https://www.prensa. com/judiciales/Corte-matrimonio-igualitario-Luis-Fabrega_0_4780022016.html

20. El Comercio. (2017, octubre 13). Fact checking a las declaraciones de «Con mis hijos no te metas» en Ecuador. https://www.elcomercio.com/tendencias/factcheckingmarcha-genero-conmishijosnotemetas-ecuador.html

21. El Siglo. (2016, julio 13). Protestan en contra del proyecto de Ley 61 sobre salud sexual. http://elsiglo.com.pa/panama/protestan-contra-proyecto-61-sobre-saludsexual/23950721

22. Escudero, Irene. (2017, noviembre 21). Las trans bolivianas se [174] quedan sin derechos. El País. https://elpais.com/elpais/2017/11/16/planeta futuro/1510837793_549748.html

23. Faludi, Susan. (1991). Backlash: The Undeclared War Against American Women. New York: Crown Publishing Group.

24. Felitti, Karina. (2011). Estrategias de comunicación del activismo católico conservador frente al aborto y el matrimonio igualitario en la argentina. Sociedad y Religión, Xxı (34), pp. 92-112.

25. Flores, Andrew \& Barclay, Scott. (2016). Backlash, Consensus, Legitimacy, or Polarization: The Effect of Same-Sex Marriage Policy on Mass Attitudes. Political Research Quarterly, 69 (1), pp. 43-56. https://doi.org/10.1177/1065912915621175

26. Fowks, Jacqueline. (2017, marzo 3). La educación sobre igualdad de género divide a Perú. El País. https://elpais.com/internacional/2017/03/03/ america/1488578133_128529.html

27. Género \& Política en América Latina (G\&PAL). (s. f.). Políticas antigénero en América Latina: estudios de caso. Sexuality Policy Watch. https://sxpolitics.org/GPAL/

28. Gianella, Camila. (2018). Movimiento transnacional contra el derecho al aborto en América Latina. En: Bergallo, Paola; Jaramillo, Isabel y Vaggione, Juan Marco (eds.). El aborto en América Latina. Estrategias jurídicas para luchar por su legalización y enfrentar resistencias conservadoras (pp. 351-378). Buenos Aires: Siglo XXI. 
29. González, Ana; Castro, Laura; Burneo, Cristina; Motta, Angélica y Amat, Oscar. (2018). Develando la retórica del miedo de los fundamentalismos. La campaña «Con Mis Hijos No Te Metas» en Colombia, Ecuador y Perú. Lima: Centro de la Mujer Peruana Flora Tristán.

30. Hamilton, Linda. (2003). Sociolegal Backlash. In: Hamilton, Linda (org.). Backlash against the ADA. Reinterpreting Disability Rights (pp. 340-394). Michigan: The University of Michigan.

31. Kuhar, Roman \& Paternotte, David. (2017). Anti-gender campaigns in Europe: Mobilizing Against Equality. New York-London: Rowman \& Littlefield International.

32. La República. (2017, marzo 3). Con mis hijos no te metas: así se desarrolla la marcha contra «ideología de género». https://larepublica.pe/sociedad/853601-conmis-hijos-no-te-metas-manifestantes-se-reunen-para-marchar-contra-la-ideologia-degenero/

33. La República. (2017, octubre 14). Marchan en diversas ciudades bajo el lema «Con mis hijos no te metas». https://www.larepublica.ec/blog/2017/10/14/marchandiversas-ciudades-bajo-lema-hijos-metas/

34. Lemaitre, Julieta. (2013). Laicidad y resistencia: Movilización católica contra los derechos sexuales y reproductivos en América Latina. México, D. F.: IIJ-UNAM.

35. López, Jairo Antonio. (2017). Movilización y contramovilización frente a los derechos LGBT. Respuestas conservadoras al reconocimiento de los derechos humanos. Estudios Sociológicos, 36 (106), pp. 161-187. https://doi.org/10.24201/ es.2018v36n106.1576

36. Mansbridge, Jane \& Shames, Shauna. (2008). Toward a Theory of Backlash: Dynamic Resistance and the Central Role of Power. Politics \& Gender, 4 (04), pp. 623634. https://doi.org/10.1017/S1743923X08000500

37. Meneses, Daniela. (2019). Con Mis Hijos No Te Metas: un estudio de discurso y poder en un grupo de Facebook peruano opuesto a la «ideología de género». Anthropologica, 37 (42), pp. 129-154. https://dx.doi.org/10.18800/ anthropologica.201901.006

38. Miskolci, Richard y Campana, Maximiliano. (2017). «Ideologia de gênero»: Notas para a genealogia de um pânico moral contemporâneo. Sociedade e Estado, 32 (3), pp. 725-748. https://doi.org/10.1590/s0102-69922017.3203008

39. Moragas, Mirta. (2020). Políticas antigénero en América Latina: El caso de la OEA. En: Corrëa, Sonia (ed.). Políticas antigénero en América Latina: Estudios de caso (pp. 5-63). Río de Janeiro: Observatorio de Sexualidad y Política.

40. Morán, José Manuel. (2018). Religión, secularidad y activismo héteropatriarcal: ¿qué sabemos del activismo opositor a los derechos sexuales y reproductivos en Latinoamérica? La Ventana, 5 (47), pp. 97-138. https://doi.org/10.32870/lv.v5i47.6637

41. Morán, José Manuel. (2019). The Geopolitics of Moral Panic: The Influence of Argentinian Neo-Conservatism in the Genesis of the Discourse of 
«Gender Ideology». International Sociology, 34 (4), pp. 402-417. https://doi. org/10.1177/0268580919856488

42. Morán, José Manuel y Morgan, Lynn. (2005). La vida no es una sola: Los usos políticos de la «vida» en Latinoamérica. Revista Culturales, 6 (1), pp. 1-38. https://doi. org/10.22234/recu.20180601.e326

43. Morán, José Manuel, Sgró, María y Vaggione, Juan Marco. (2012). Sexualidades, desigualdades y derechos. Reflexiones en torno a los derechos sexuales y reproductivos. Córdoba: Universidad Nacional de Córdoba.

44. Murillo, Álvaro. (2013, agosto 11). Católicos y protestantes se alían en Costa Rica en una marcha «por la vida». El País. https://elpais.com/internacional/2013/08/11/ actualidad/1376176524_110956.html

45. Olayo Orbegozo, Fernando. (2017, agosto 28). PJ anula parcialmente enfoque de igualdad de género en currículo escolar. El Comercio. https://elcomercio.pe/peru/ judicial-anula-enfoque-igualdad-genero-curriculo-escolar-noticia-453837-noticia/

46. Pérez, Verónica y Rocha-Carpiuc, Cecilia. (2020). The Postreform Stage: Understanding Backlash against Sexual Policies in Latin America. Politics \& Gender, 16 (1). https://doi.org/10.1017/S1743923X20000069

47. Rodríguez García, Arturo. (2016, mayo 19). Iniciativa de Peña incluye adopción de parejas gay. Proceso. https://www.proceso.com.mx/nacional/2016/5/19/ iniciativa-de-pena-incluye-adopcion-en-parejas-gay-164483.html

48. Ruibal, Alba. (2014). Feminismo frente a fundamentalismos religiosos: [176] Mobilização e contramobilização em torno dos direitos reprodutivos na América Latina. Revista Brasileira de Ciência Política, (14), pp. 111-138. https://doi.org/10.1590/0103335220141405

49. Ruibal, Alba. (2015). Movilización y contra-movilización legal. Propuestas para su análisis en América Latina. Política y Gobierno, 22 (1), pp. 175-198.

50. Sáez, Macarena y Morán, José Manuel. (2016). Sexo, delitos y pecados. Intersecciones entre religión, género, sexualidad y el derecho en América Latina. Washington: American University.

51. Semana. (2016, agosto 11). «No se ha implementado la ideología de género»: Santos. https://www.semana.com/nacion/articulo/manuel-contra-el-matoneo-santosdice-que-el-gobierno-no-implementa-ideologia-de-genero/486519/

52. Semana. (2016, septiembre 13). Proponen frente latinoamericano contra la ideología de género. https://www.semana.com/nacion/articulo/frente-latinoamericanoa-favor-de-la-familia-y-contra-la-ideologia-de-genero/493623/

53. Tarrow, Sidney. (2004). El poder en movimiento. Los movimientos sociales, la acción colectiva y la política. Madrid: Alianza. 
54. Tilly, Charles. (2011). Describiendo, midiendo y explicando la lucha. En: Auyero, Javier y Hobert, Rodrigo (eds.). Acción e interpretación en la sociología cualitativa norteamericana (pp. 13-38). Quito: Flacso-Ecuador.

55. Transnacionales de la fe. (s. f.). El crecimiento del poder político evangélico y su agenda fundamentalista en América Latina con el apoyo de la Casa Blanca. https:// transnacionalesdelafe.com/

56. Vaggione, Juan Marco. (2005). Reactive Politicization and Religious Dissidence: The Political Mutations of the Religious. Social Theory and Practice, 31 (2), pp. 165-188. https://doi.org/10.5840/soctheorpract200531210

57. Vaggione, Juan Marco. (2010). El activismo religioso conservador en Latinoamérica. Córdoba: Ferreyra.

58. Vaggione, Juan Marco. (2012). La "cultura de la vida». Desplazamientos estratégicos del activismo católico conservador frente a los derechos sexuales y reproductivos. Religião e Sociedade, 32 (2), pp. 57-80. https://doi.org/10.1590/S010085872012000200004

59. Vaggione, Juan Marco. (2020). The Conservative Uses of Law: The Catholic Mobilization against Gender Ideology. Social Compass, 67 (2), pp. 252-266. https:// doi.org/10.1177/0037768620907561

60. Vaggione, Juan Marco y Mujica, Jaris. (2013). Conservadurismos, religión y política. Perspectivas de investigación en América Latina. Córdoba: Ferreyra.

61. Vinjamuri, Leslie. (2017). Human Rights Backlash. Cambridge: Cambridge University. 